\title{
CREATING SUSTAINABLE CITIES THROUGH DISASTER RESILIENCE IN TURKEY
}

\author{
E. Alarslan ${ }^{1}$ \\ ${ }^{1}$ The Ministry of Environment \& Urbanization, DG Infrastructure \& Urban Transformation Services, Mustafa Kemal Mahallesi, \\ Eskişehir Devlet Yolu, 06650 Çankaya/Ankara, Turkey - ebrua@ csb.gov.tr
}

KEY WORDS: Sustainable Development Goals by 2030, Sustainable Cities, Disaster Resilience, Recent Studies in Turkey, Urban Risks

\begin{abstract}
:
By 2050, almost 66 per cent of the world's population will live in urban areas. While the urban settlements provide better living opportunities for people, they are also tremendously exhausting natural resources. Thus, as one of the 17 sustainable development goals, "sustainable cities and communities" is promoted by the United Nations. Over the course of the last 70 years, Turkey has experienced one of the most significant urbanization experiences in the world. Recently, cities accommodate over 75 percent of the country's population. Furthermore, they are prone to high disaster risks due to their dense population and construction in Turkey. Of note, the two perilous earthquakes in 1999 (Izmit \& Duzce), provided Turkey significant experiences. They gave rise to reviewing the entire disaster mitigation system. Nevertheless, the earthquake in the City of Van (24.10.2011) revealed some deficiencies in the process of implementing disaster mitigation measures. To remedy these deficiencies, the Ministry of Environment and Urbanization (MoEU) prepared a new law on "Transformation of Areas under the Disaster Risks" (Law No. 6306). The law sets out principles and standards of disaster mitigation and process and procedures with respect to areas prone to disaster risks as well as buildings at risks in and out of disaster prone areas. In this paper, the aforementioned experience of Turkey will be reviewed in terms of sustainable cities and communities goal. Furthermore, the relevant implementations will be reviewed with a view to creating better solutions as well as decreasing undesired consequences such as compulsory displacement of people and degradation of urban environment.
\end{abstract}

\section{INTRODUCTION}

Urban settlements are becoming main habitats for human beings year by year in the $21^{\text {st }}$ century. According to the UN figures, 66 $\%$ of the world population will be living in urban areas by 2050 (The United Nations, 2014). A rapid increase both in the number of urban settlements and urban populations attracts the attention of scientists, researchers, policy makers, governors, and international organizations. In New York, the High-level Plenary Meeting of the General Assembly of the UN in 2015, all member states agreed on 17 sustainable development goals by 2030. One of those goals is Goal 11: Sustainable Cities and Communities (SDG 11) which addresses the risks and expectation for better and liveable life standards in urban areas (UN, 2015).

As a rapid urban population increasing country, Turkey put significant emphasis on sustainable urban development. Especially to consider high disaster risks in urban settlements, the new urban transformation program has been executing by the Ministry of Environment and Urbanization since 2012. In this paper, the efforts of the Ministry of Environment of Urbanization will be analyzed in terms of strengths and weaknesses of the applied urban transformation program. In the mean time, the contributions of the program to the "Sustainable Cities and Communities" will also be evaluated.

\section{A SYNOPTIC FOR SUSTAINABLE DEVELOPMENT GOALS AND SUSTAINABLE CITIES}

\subsection{The Concept of Sustainable Development}

The concept of "sustainable development" can be described as a "development that meets the needs of the present without compromising the ability of future generations to meet their own needs" (The World Commission on Environment and Development, 1987). The aforementioned definition was initially used in the $2^{\text {nd }}$ part of the Report of "Our Common Future" by the World Commission on Environment and Development and became very well-known. The concept of sustainable development had three pillars, namely social, environmental, and economic (see fig.1).

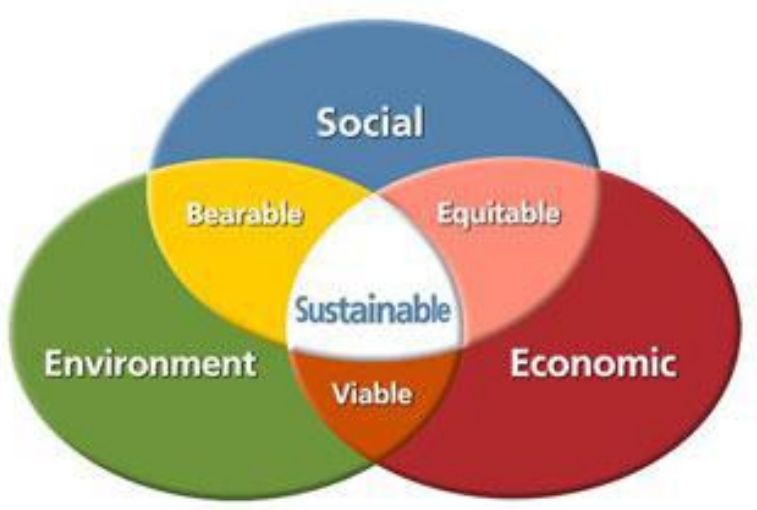

Figure 1. Three pillars of sustainable development

According to the chronological records, the concept of "sustainability" was initially used in the Book of "Silent Spring" written by Rachel Carson in 1962. The book was written on environmental protection issues and especially negative impacts of agricultural chemicals on living creatures. Later on, the concept of sustainability was evolved to be used as a sustainable development that is in the core agenda of today. 
Since the first use of the concept in 1962, there are some major milestones about the sustainable development. In 1987, the Report of "Our Common Future", also called "Brundtland Report" was a main attempt to address environmental anxieties for the future generation by the World Commission on Environment and Development (The United Nations, 1987). In The HABITAT II Conference/City Summit which was held in Istanbul in 1996, the standard of environmental management, "ISO 14001" was formally adopted. In 1999, the first global sustainability index was launched. In 2002, the World Summit on Sustainable Development was held in Johannesburg, and the Global Reporting Initiative (GRI) was promulgated. The Habitat III was the United Nations Conference on Housing and Sustainable Urban Development took place in Quito, Ecuador, in 2016. In addition to the major milestones mentioned above, hitherto, numerous events and programs have been organized with a view to promoting sustainable development actions (International Institute for Sustainable Development, 2017).

\subsection{The Goal of Sustainable Cities and Communities among 17 Sustainable Development Goals}

The concept of sustainable urban development has a high potential to provide guidance to resolve recent global urban problems. In this respect, the goal of "Sustainable Cities and Communities-SDG 11" among 17 sustainable development goals possibly facilitates the design of an effective road map. The SDG 11 also needs interoperability with other sustainable development goals in leading to create sustainable cities and communities such as Goal 3:Good Health and Well-being, Goal 4: Quality Education, Goal 6: Clean Water and Sanitation, Goal 7: Affordable and Clean Energy, Goal 8: Decent Work and Economic Growth, Goal 9: Industry, Innovation and Infrastructure, Goal 10: Reduced Inequalities, Goal 12: Responsible Consumption and Production, Goal 13: Climate Action, and Goal 17: Partnership for Goals (see fig.2).

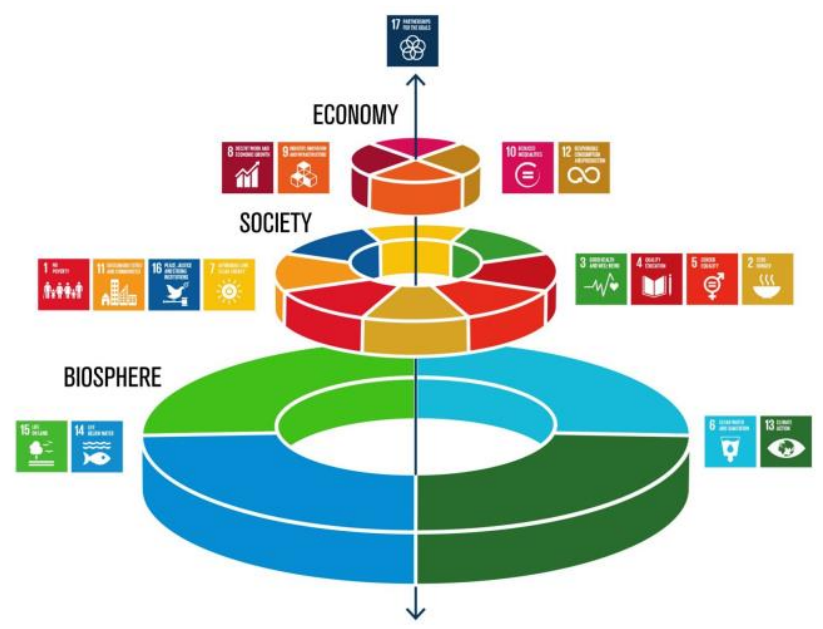

Figure 2. 17 Sustainable Development Goals

There are some urban development models which also serve to the purpose of the Goal "Sustainable Cities and Communities" as well as provide some complementary actions. Those models are smart cities, green/eco-cities, liveable cities, branding cities, inclusive cities, and resilient cities. Despite of thematic differences, all those models have many common programs to promote sustainable cities and communities in the world. The resilient city model among the aforementioned ones requires more emphasis in compliance with the context of this paper.
The concept of disaster resilience has been developed in the 21 st century, in lieu of the previous concept of disaster resistance. Unlike the concept of disaster resistance, the concept of disaster resilience emphasizes elasticity and flexibility in coping with the particular challenges of the various natural disasters (Vale et al., 2005). Especially, with regard to the uncertainty of natural disasters, the term of resilience can provide a better guidance to produce effective disaster mitigation approaches in urban settlements. The disaster resilience concept is defined in terms of the adaptation capacity of a settlement system (built up and non-built up environment as well as community of life) potentially exposed to natural hazards with a view to maintaining or restoring an acceptable level of functioning and structure (Greiving et al.,2006).

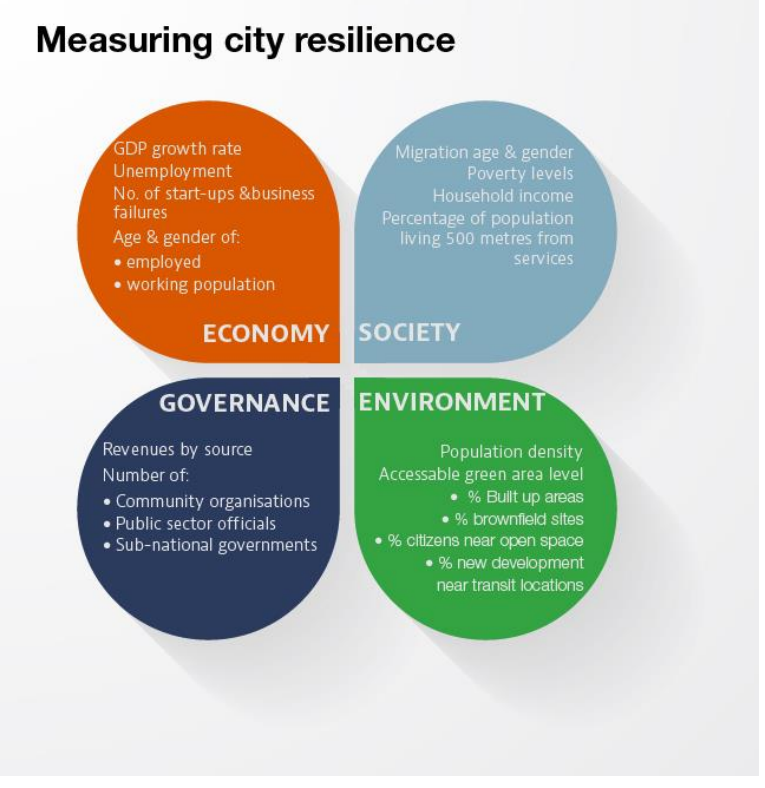

Figure 3. UNISDR, The Campaign of Making Cities Resilient

To develop a resilient city model requires drawing a disaster risk profile of a given city as well as developing key policies, strategies, and measures to reduce the relevant risks in the short, medium-, and long-terms. Furthermore, stakeholder participation at the micro, meso, and macro level implementations should be encouraged and promoted. In other words, in order to create sustainable cities, the social, economic, and environmental issues in designing the development programs/disaster mitigation plans/spatial development plans of the disaster prone cities should be taken into consideration.

In terms of resilience, the United Nations International Secretary of Disaster Risk Reduction (UNISDR) that has been executing some programs and actions for global risk reduction such as the Sendai Framework for Disaster Risk Reduction 2015-2030 and the "Making Cities Resilient" Campaign plays an important role. In the frame of aforementioned efforts and other relevant activities, UNISDR also aims at combining disaster risk reduction endeavours with the objectives of the SDG 11: Sustainable Cities and Communities (UNISDR, 2017).

To carry the step of disaster resilience actions further, the following key questions can be formulated in the light of the requirements of sustainable cities and efforts of UNISDR: 
> What approaches/instruments do governments take for promoting resilient and sustainable cities?

$>$ What types of difficulties/weaknesses can be described in terms of collecting/exchanging/producing the relevant data?

$>$ How can an effective multi-stakeholder contribution process be designed through the implementations of SDG 11 ?

$>$ Who are the key stakeholders to promote sustainable cities and communities?

$>$ What types of challenges and difficulties can be expected in financing the relevant operations to promote sustainable and resilient cities?

$>$ How can resilience measures be integrated into sustainable city management systems?

\section{DISASTER RESILIENCE IN TURKEY}

\subsection{A Review about the Recent Developments}

Because of its geologic, topographic and climatic attributes, Turkey has frequently been confronted with many different types of natural disasters, namely earthquakes, floods, landslides, and avalanches. Among these natural disasters, earthquakes have the most detrimental effects on the settlements in Turkey (TR Prime Ministry Disaster and Emergency Management Directory, 2012).

Especially since the 1950s, urban settlements in Turkey have been the main centers of increasing population and construction. According to the statistical figures, while $25 \%$ of the population previously lived in the cities, today, over $70 \%$ of the country's population resides in urban areas. Based on the urbanization rate over $4 \%$, Turkey is one of fastest urbanizing countries in the world (The World Bank, 2015). Due to its fast urbanization rate, Turkish cities have been faced with the problems of agglomerations, squatter settlements, and other problems in the provision of urban amenities as well as high disaster risks. According to the $10^{\text {th }}$ Development Plan of Turkey, the most significant urban problems are described as rapid and pseudo urbanization, insufficient numbers of descent housing units, traffic congestions, lack of urban safety and infrastructure, social cohesion, and environmental degradation. To surmount on those problems, a set of recommendations were formulated in the $10^{\text {th }}$ Development Plan. These include creating liveable cities by relevant operations in existing settlements and preparing integrated disaster hazard and risk plans to mitigate both disaster and climate change potential impacts on cities (The $10^{\text {th }}$ Development Plan of Turkey 20142018).

Urban settlements in Turkey are still at high risk of natural disasters due to dense construction parallel with the population increase. The extensive natural disaster experience of Turkey over many centuries invigorated efforts to develop disaster mitigation capacities. Especially, after two perilous earthquakes in 1999 (Izmit \& Duzce), Turkey had remarkable lessons learnt. These lessons learnt gave rise to reviewing the entire disaster mitigation system. Many initiatives and ongoing studies on legislation, institution-building, insurance, and quality control look promising for disaster resilient settlements. Nevertheless, the earthquake in the city of Van $(24.10 .2011)$ revealed some deficiencies in the implementation process. To find out an effective method to surmount these deficiencies, the Ministry of Environment and Urbanization prepared a new law namely, Transformation of Areas Under the Disaster Risks (Law No. 6306). The law entered into force on 31.5.2012. The scope of the law is to determine principles and standards of disaster mitigation and recovery process and procedures in the areas prone to disaster risks as well as buildings at risks in and out of disaster prone areas. Since urban settlements are densely populated and constructed areas in such an increasing population country like Turkey, the main focus of implementation is on urban settlements in the frame of aforementioned law.

In this respect, it is expected to design a road map to execute the transformation process priorly in urban settlements. The road map requires setting relevant principles and standards for the urban transformation process and procedures as well as capacity development for technical staff and key executives. Consequently, the Ministry of Environment and Urbanization expects to achieve the following goals:

- To transfer the knowledge and experience attained from the road map into a regulation to guide local authorities how to implement the urban transformation process.

- To lessen urban environmental degradation

- To create awareness on how to build sustainable urban settlements

The urban transformation process is constituted with multidimensional work packages. It does not only cover the process of reconstruction of the risky buildings but also integrated spatial planning approach to serve sustainable development, financial models to facilitate the payments of middle and low income group home owners, as well as environmental friendly methods to prevent environmental degradation in and around urban areas. In this respect, the Ministry of Environment and Urbanization aims at enacting comprehensive legislation to guide for better implementations. Thus, the Ministry is going to organize various workshops, seminars, and local meetings to invite relevant public, central and local authorities, private company representatives, academics, scientists, researchers, NGOs and other citizen groups, and media members to create a common mind. It is believed that all these valuable inputs will have valuable contribution to draw an effective road map for the urban transformation process. Furthermore, the General Directorate of Infrastructure and Urban Transformation Services (DGI\&UTS) which is in charge of executing all relevant works in the process of urban transformation performed a cooperative work with a group of the World Bank experts in Turkey. The consultants and experts of the World Bank prepared "A Guide for Urban Transformation" and organized "An Urban Design Charette" in the technical assistance program for Turkey in the period of 2012-2015.

\subsection{Critical Analysis for Better Implementations}

In the light of two aforementioned documents, namely the Guide for Urban Transformation and the Report of the Urban Design Charette ${ }^{1}$, DGI\&UTS had a chance to understand

${ }^{1}$ The term "Charette" (little cart) appeared in the late 1800's. Architecture students at the Ecole Des Beaux-Arts in Paris who needed to rush their designs to their instructors, placed their drawings on a cart which was called a charette. Later the word broadened in meaning and came to describe any intense, short-term design project. Today the word is used by the architectural and design community at large to describe any intense, on-the-spot design effort (https://www.urbandictionary.com/define.php?term=Charrett e). 
weaknesses and strengths of its administrative, financial, and technical process.

Initially, consultants made a series of visits to the executives and technical staff of DGI\&UTS to understand the process, procedures and dynamics of urban transformation activities. Furthermore, they reviewed the legal documents and policy papers of the central government and the Ministry of Environment and Urbanization about urban development and risk mitigation issues. While the consultants finalized the collection of the relevant data through official visits and legal documents, they proposed a guide for better implementation and a design charette for effective results by the participation of stakeholders.

In the Guide for Urban Transformation (GUT), the consultants set out guidance in the stages of (i) risk detection, (ii) project application, (iii) project design development, (iv) implementation of project, (v) post occupation evaluation following the completion of the project. In the GUT, especially in the project application and design development stages, issues and the elements of the projects are reviewed in the guidance of the "traffic light" categorisation of risk at the low, medium and high levels (see fig.4).

\section{Risk Indicator-Compliance with Planning Guidelines}

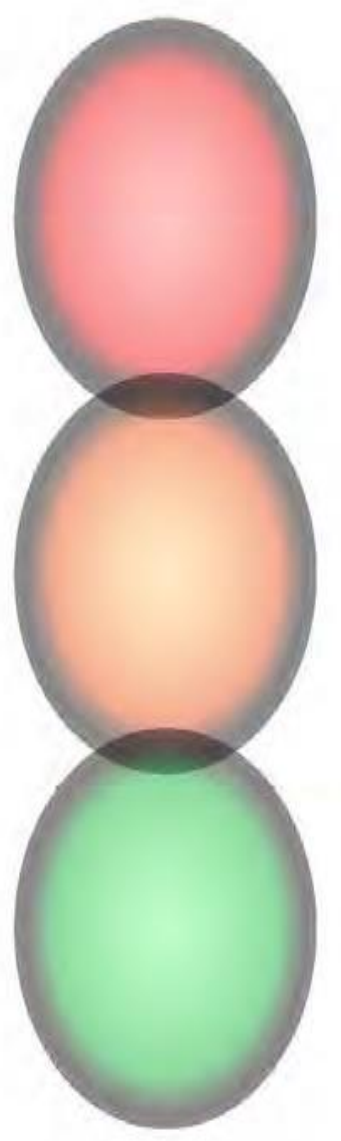

The project is broadly compliant with national and local planning guidelines, has received outline consent but critical non-compliances and contentious issues have been identified as requiring changes to the detail designs.

The project is generally compliant with national and local planning guidelines, has received outline consent but several minor noncompliances have been identified in the detailed designs which may require changes.

The project is fully compliant with national and local planning guidelines, has received outline consent and the detailed designs have been cleared informally with the municipality

Figure 4. An Example of "Traffic Light Categorization of Risk" in the Guide for Urban Transformation prepared for the Ministry of Environment and Urbanization by the World Bank

According to the description of risks, DGI\&UTS has a chance to produce a decision whether the aforementioned risk is bearable or not. In addition to the practical method to detect the level of risk, the consultants also proposed a "design charette" approach to lead to stakeholder participation in the urban transformation projects. This approach facilitates recognition of a project by different stakeholders while the implementation process can develop by the volunteer support of different groups such as municipalities, chambers of planners, citizens. The Sahinbey District Municipality in the City of Gaziantep/TURKEY was selected a pilot area to perform the design charette approach. The source of the risk area stems from the geological instability and failure. Thus, almost all property owners (houses + shops) are subject to eviction. Furthermore, many property owners might need to move to another district after the completion of the project due to higher cost of living in their former district.
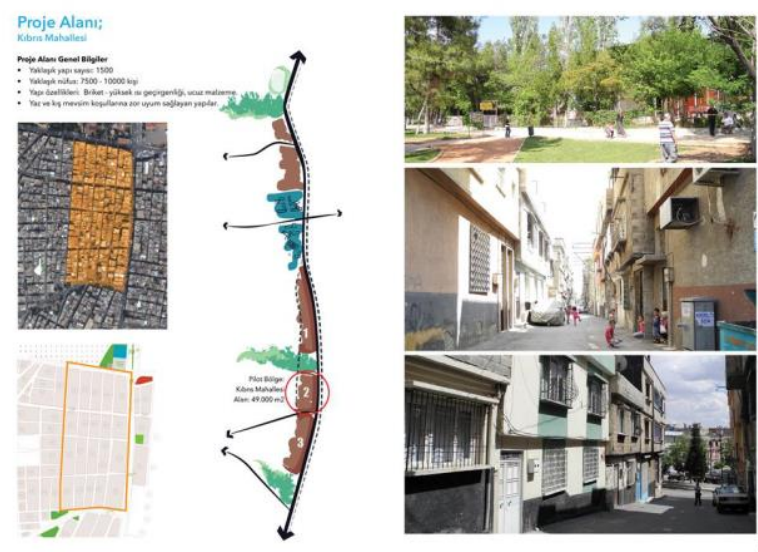

Photo 1. The Pilot Area for the Design Charette, Şahinbey, Gaziantep, TURKEY

In compliance with the principles of the "Design Charette", the consultants organized sets of meetings with executives, policy/decision makers, experts, citizens, and private volunteer organizations. Initially, the first series of meetings was organized with the decision makers of the Ministry of Environment and Urbanization, the Metropolitan Municipality of Gaziantep, and the District Municipality of Sahinbey to generate effective solutions for better implementations. Later on, a number of meetings were organized for the participation of experts and citizens to find out the optimum design for their newly developed residential area.

The recent attempt of Turkey, namely the urban transformation program initiated in 2012 , is duly admitted by the citizens who are aware of the risks threatened their settlements. However, the process and procedures need to be improved with a view to creating sustainable urban settlements. Especially, some problems create challenges in the success of the urban transformation program such as weaknesses of financial instruments, misguidance by building contractors in creating expectation for more gains by property owners, compulsory displacement of people, and degradation of urban environment. Thus, the Guide for Urban Transformation and the Design Charette Report are two significant documents with a high potential to provide guidance.

\section{THE CONTRIBUTION OF TURKEY TO THE GOAL OF SUSTAINABLE CITIES AND COMMUNITIES}

Likewise achieving to the targets of 17 sustainable development goals, "Sustainable Cities and Communities-SDG 11 " requires the partnership of governments, academia, private sector representatives, civil society and citizens. To clarify the 
potential contributions of Turkey as a Member State, the following targets of the SDG 11 need to be reviewed (UNDP, 2017):

- To ensure access for everybody to adequate, safe and affordable housing and basic services as well as to upgrade slums

- To provide access to safe, affordable and sustainable transport systems for all, improving road safety, notably by expanding public transport, with special attention to the needs of those in vulnerable situations, women, children, persons with disabilities and older persons

- To enhance inclusive and sustainable urbanization and capacity for participatory, integrated spatial planning and programming in all urban settlements

- To strengthen efforts to protect and conserve the world's cultural and natural heritage

- To achieve a significant reduction in the number of deaths and the number of people affected by economic difficulties and disasters including water-related disasters, with a focus on protecting the poor and people in vulnerable situations

- To reduce the adverse human impacts on urban environment by paying special attention to air quality and waste management

- To provide universal access to safe, inclusive and accessible, green and public spaces, in particular for women and children, older persons and persons with disabilities

- To support positive economic, social and environmental links among urban, peri-urban and rural areas by strengthening national and regional development planning

- To adopt and implement integrated policies and plans towards inclusion, resource efficiency, mitigation and adaptation to climate change, resilience to disasters as well as to develop and implement necessary actions in line with the Sendai Framework for Disaster Risk Reduction 20152030, holistic disaster risk management at all levels

- To support least developed countries, including financial and technical assistance, in building sustainable and resilient buildings utilizing local materials

In accordance with the targets of SDG 11, the main actor in Turkey is the Ministry of Environment and Urbanization. In addition to its implementations about the environmental, spatial planning and urban development issues, the institutional vision and policies have been serving to the targets described above. The Ministry has envisaged the development of cities which are mainly populated settlements through branding cities by 2023 as the $100^{\text {th }}$ anniversary of the Modern Republic. With this vision, the Ministry aims at promoting welfare of the country as well as well-being of the people who live in urban settlements. These issues are also underlined in the recent program of the central government (The Ministry of Environment and Urbanization, 2015). In addition to its major responsibilities to serve the purpose of the SDG 11, the Ministry of Development and municipalities are other key actors having great potential to make relevant contributions.
According to the recently prepared Report of the World Bank, namely "Turkey Urbanization Review", the urban development experience of Turkey was described as a good model for countries experiencing rapid urbanization. Especially, the efforts of Turkey in provision of affordable housing, infrastructure and other urban utilities have great potential to provide guidance to the countries that have similar difficulties. However, Turkey still needs to upgrade its capabilities for more institutional cooperation and interoperability (The World Bank, 2015).

\section{CONCLUSION}

As already underlined, urban settlements gain importance by their increasing population year by year. Thus, the Member States of the United Nations agreed on the importance of the Goal of "Sustainable Cities and Communities" in addition to the other 16 goals in 2015. The requirements of the Goal of "Sustainable Cities and Communities" can be briefly formulated into four issues, namely (i) urban safety, (ii) environmental protection, (iii) conservation of cultural and natural assets, and (iv) resilience for disaster risks and adaptation to climate change. Turkey, with its rapid urbanization rate, has been aware of its high urban risks stemming from natural disasters. The recent attempt of Turkey about the urban transformation program also serves to the purpose of promoting sustainable cities and communities. In this respect, the main actor of Turkey is the Ministry of Environment and Urbanization.

Since 2012, the Ministry of Environment and Urbanization has been executing the relevant process and procedures for the program of urban transformation. After the Law of "Transformation of Areas Under the Disaster Risks (Law No. 6306)" entered into force, the Ministry started to implement the transformation process priorly in urban settlements. In terms of better implementations, the Ministry is in an endeavour to develop tools and procedures of the urban transformation activities. According to the Report of "Turkey Urbanization Review" prepared by the World Bank, the urban development experience of Turkey was described as a good model for countries experiencing rapid urbanization. However, many hard works need to be carried out with a view to building better cooperation among different institutions and to maintain interoperability.

\section{REFERENCES}

Greiving, S. et al.; (2005): “ARMONIA Project: Deliverable 1.3 Report on the definition of possible common procedures and methodologies of spatial planning for natural hazards, to inform the development of a new spatial planning standard for the EU", Dortmund, Germany.

International Institute for Sustainable Development, 2017. Sustainable Development Timeline. https://www.iisd.org/pdf/2012/sd_timeline_2012.pdf

ISOCARP, 2016. New Urban Agenda-21.10.2016, United Nations Conference on Housing and Sustainable Urban Development Habitat III- Quito Declaration. https://isocarp.org/app/uploads/2016/11/New-Urban-AgendaPlanning.pdf

The $10^{\text {th }}$ Development Plan of Turkey (2014-2018) issued in the official gazette of 6.7.2013, no. 28699, pp.117-118. 
The Law of Transformation of Areas under the Disaster Risks (Law No. 6306), issued in the official gazette of 31.5.2012, no. 28309.

The Ministry of Environment and Urbanization, 2015. The Strategic Plan 2015-2017, Ankara, Turkey.

The Strategy and Action Plan of Integrated Urban Development: KENTGES (2010-2023), issued in the official gazette of 4.11.2010, no. 27749, http://www.kentges.gov.tr/_dosyalar/kentges_en.pdf..

The UN-HABITAT, 2015. Urban Solutions, Nairobi, Kenya https://www.unhabitat.org

The United Nations Department of Economic and Social Affairs, 2014. World Urbanization Prospects-The 2014 Revision, New York, USA.

The United Nations, 1987, The World Commission on Environment and Development Report:. Our Common Future, Chapter 2: Towards Sustainable Development From A/42/427. http://www.un-documents.net/ocf-02.htm

The United Nations, 2015. Draft Outcome Document of the United Nations Summit for the Adoption of the Post-2015 Development Agenda, A/69/L.85, New York, USA.

The World Bank Social, Urban, Rural, Resilience Global Practice Group, 2015. Turkey Urbanization Review-Rise of the Anatolian Tigers, Washington DC, USA.

TR Ministry of Development, 2016. Report on Turkey's Initial Steps Towards the Implementation of the 2030 Agenda for Sustainable Development, Ankara, Turkey.

TR Prime Ministry Disaster \& Emergency Management Directory (2012): National Earthquake Strategy and Action Plan 2012-2023, Ankara, http://www.afad.gov.tr.

UNDP (United Nations Development Program), 2017. Sustainable Development Goals Reports,: http://www.undp.org

UNESCO, 2017. 17 Sustainable Development Goals, http://en.unesco.org/sdgs

UNISDR, 2017. https://www.unisdr.org.

Vale, L. J./ Campanella, T. J. (Eds.2005): Resilient City: How Modern Cities Recover from Disaster, Oxford University Press, UK. 